\title{
ARTÍCULO
}

\section{Pensar la colección Cine y Derecho a partir de Mario Ruiz Sanz Rethinking the Collection Cine y Derecho from Mario Ruiz Sanz}

\author{
Raúl Susín Betrán \\ Área de Filosofía del Derecho \\ Facultad de Ciencias Jurídicas y Sociales \\ Universidad de La Rioja
}

Fecha de recepción 01/06/2019 | De publicación: 27/06/2019

Sirvan estas líneas como una modesta aportación al reconocimiento que los compañeros del área de Filosofía del Derecho de la Universidad de Valencia están realizando a Mario Ruiz Sanz. Por eso quizás lo primero sea agradecerles la invitación que me han realizado a participar en esta mesa y poder, así, contribuir también a este reconocimiento de alguna manera.

Este seminario lleva por título Seminario Mario Ruiz. Cine, Literatura y Derecho, y esto me hace recordar una reflexión de Cabrera Infante quien, en su faceta de crítico de cine, decía algo así como que hablar de una película y decir de ella algo más que "me gusta" o "no me gusta", era hacer literatura. Y tal vez esa sea precisamente mi vía de escape en este momento, porque me produce una cierta dificultad hablar de cine y derecho en Valencia, donde tanto se ha trabajado sobre este tema, sede de la editorial Tirant lo Blanch y delante de, entre otros, el director de la colección Cine y Derecho de dicha editorial, responsabilidad -la de la dirección de la colección- en la que también de forma informal tuvo que ver Mario Ruiz.

Y quizás, en este mundo de paradojas, también la opción más prudente sea la opuesta a la de hacer literatura; quizás la opción sea la del silencio, entendido este como una herramienta más del lenguaje no verbal y sobre los que Mario, como veremos más adelante, decía "que hablaban". Un silencio que, por otra parte, es algo más característico del cine que de la televisión; y como una demostración de que es el cine quien se impone en esta especie de confrontación que tiene con aquella -y no al contrario, como nos podría parecer-, sus técnicas y lenguajes -los del cine- se están 
extendiendo a las series de televisión, que comienzan a dejarse colonizar por aquel y de lo que, por ejemplo, la reciente serie Gigantes de Enrique Urbizu podría resultar ser un buen ejemplo ${ }^{1}$

En todo caso, en la sesión que me corresponden intervenir ("Cine y derecho". Una colección de Mario Ruiz) me puedo atrever a aportar algún comentario sobre lo que significa la colección de Cine y Derecho de la editorial Tirant lo Blanch, a la que Mario estaba vinculado por esa labor informal de codirección y también, como referencia de importante valor simbólico, por ser el responsable del primer número que abrió dicha colección allá por los años 2002-2003, El verdugo: un retrato satírico del asesino legal.

En este sentido, creo que la aportación principal de esta colección, su aportación nuclear, ha sido y es la de contribuir a hacer realidad eso en lo que tanto se insiste -y a lo que tanto nos resistimosen las universidades: que el derecho tiene múltiples dimensiones y que su conocimiento exige no solo trabajar con leyes, manuales, apuntes (algunos de ellos heredados y con tristes tonos amarillentos por efecto del paso del tiempo)... y aprenderse de memoria leyes, normas, preceptos, conceptos jurídicos.... A mi entender, la aportación principal de esta colección es la de poner de manifiesto que el derecho, y su conocimiento, es algo más que, por así decirlo, una dimensión normativa en papel; es algo complejo y entrelazado para lo que se exige, también, una forma de aprender en la que la combinación de Cine, Derecho y Literatura tienen mucho que aportar. Además, y vinculada con esta aportación central, esta colección -respetando el necesario rigor académico- también trata de romper esas quiebras en la transmisión del mensaje que, en ocasiones, provoca la tendencia que tenemos los juristas a lo críptico, a la opacidad y a una cierta incomunicación. Por eso, precisamente, no está de más recordar aquí la recomendación que desde la editorial y desde los responsables de la colección reciben los autores cuando realizan una propuesta de publicación: lo que vas a hacer no es un trabajo de tesis donde debas demostrar todo lo que has leído y todo lo que sabes sobre un tema; así, por ejemplo, evita ese pesado recurso tan común en las ciencias jurídicas a citar constantemente a pie de página y que lleva casi a crear un segundo texto; y, aunque sea por una vez, piensa en quién te va a leer, si quieres que alguien te lea, que esa es otra historia.

\footnotetext{
${ }^{1}$ En la presentación de la serie para TV Gigantes, su director, Enrique Urbizu, entre otras cosas, vino a decir que el silencio en el lenguaje de la televisión no estaba, digamos, bien considerado, que había "miedo al silencio y a la oscuridad". Sin embargo, su serie recurre a los mismos, a los silencios, al igual que otras que el mismo Urbizu nos recuerda, como Breaking Bad o The Wire; lo que, de alguna manera, puede interpretarse -como recogemos arriba-como una colonización del cine sobre la TV, como que es el cine el que se impone en el ámbito de los lenguajes propios.
} 
La recomendación anterior no solo tiene que ver con un siempre aconsejable control de egos y de retóricos ejercicios de autocomplacencia; sobre todo, tiene mucho que ver con el potencial lector de los trabajos publicados en la colección. El lector de estas publicaciones no es un lector generalista, tipo el gran público al que van dirigidos los best sellers; pero tampoco se puede decir que sea alguien que busque con estas lecturas únicamente resolver cuestiones técnico-científicas precisas. La colección busca equilibrios y simetrías entre juristas y cinéfilos; al tiempo que tampoco renuncia a trazar puentes por los que puedan transitar con cierta facilidad aquellas gentes que manifiesten un mínimo de curiosidad por los temas que entrelaza la colección Cine y Derecho.

$\mathrm{Y}$ en esta tarea de tender puentes a lo largo de las diferentes publicaciones aparecidas en la colección, la Filosofía del Derecho ha tenido una buena parte de responsabilidad y protagonismo poniendo en relación, como ha hecho en otras ocasiones, saberes diversos con el estudio y conocimiento del fenómeno jurídico. Es cierto que no solo podemos encontrar aportaciones provenientes de esta disciplina en la colección, pero, como recordó Benjamín Rivaya en las XXII Jornadas de la Sociedad Española de Filosofía Jurídica y Política, celebradas en Logroño en marzo de 2009, existe un vínculo entre la Filosofía del Derecho y Derecho y Cine, y el motivo de que exista este vínculo se debe "a la función que tradicionalmente ha asumido la filosofía jurídica, (...) la función decía- de poner en relación saberes y fenómenos diversos con el estudio y el fenómeno jurídico (Derecho y Literatura, Derecho y Sociedad, Derecho y Política, Derecho y Antropología, etc.)" (Rivaya 2010, 220).

Por otra parte, no podemos si no también recordar aquí que la intervención de Benjamín Rivaya en dichas Jornadas formó parte de una sesión temática sobre Cine y Derecho que sirvió -en palabras del propio Rivaya- como "un acto de puesta de largo de Derecho y Cine", y donde, entre otros (Ricardo García Manrique, María José García Salgado, Juan Antonio Gómez García, José Luis Pérez Triviño) intervino Mario Ruiz con una reflexión a la pregunta: “¿Es conveniente enseñar derecho a través del cine?", para lo que se sirvió, creo recordar, de imágenes de La Pasión de Juana de Arco de Carl Theodor Dreyer y en donde afirmó -y de nuevo nos aparece el silencio- que el citado director 
“nos había enseñado (...) que el silencio no es mudo, sino pasión callada que protesta y grita desde las entrañas",2.

Volviendo a la colección, varias decenas de títulos en ella (unos 50 a fecha de hoy), y también en la "satélite" Cine y Derecho Temática (en marcha desde hace unos pocos años), nos hablan de que no se trata para nada de una relación efímera. En tiempos de modernidad líquida y donde de fondo podemos escuchar una especie de música que nos enfrenta a un juego de las sillas que da vértigo y nos exige movimiento continuo, también en el mundo editorial, el Cine y el Derecho prolongan una relación que se muestra ya estable y a la que la colección ha aportado no poco, facilitando que la miremos como algo habitual. Pero, sobre todo, con la colección se está reconociendo, de alguna manera, la capacidad que tiene el cine -considerado en el siglo XX como la forma de espectáculo por antonomasia- para empaparse de derivas sociales y, en ellas, de las jurídicas, políticas, filosóficas...

A lo largo de estas decenas de títulos y por distintas vías, sea por temas, por películas, analizando el tratamiento que el derecho le da a los distintos géneros cinematográficos o utilizando el cine para introducirnos en las distintas ramas de los saberes jurídicos, en esta colección se ha hecho un trabajo en una doble dirección: complejizando y simplificando; enredando y desenredando. Se simplifica el fenómeno jurídico, se intenta amortiguar la tendencia citada a la opacidad y a la incomunicación que tenemos los juristas y con la que contaminamos lo que hacemos; se desenredan temas que resultan complejos por su contenido y por el lenguaje con el que se tratan. Pero también con la relación Cine y Derecho se complejiza y se enreda el mismo fenómeno jurídico: se parte de una película, de un personaje, y desde allí se trasciende lo que puede entenderse como la anécdota para abrirnos las opciones, las perspectivas y las miradas, sin por ello -insisto- dejar de acercarnos de forma más comprensible a lo que en no pocas ocasiones se nos presenta como algo árido, lejano y oscuro.

De cualquier manera, en ambas direcciones, enredando y desenredando, complejizando y descomplejizando, se nos facilita una manera de mirar distinta, casi anormal, y de todo ello sobran buenos ejemplos, y bien escritos, en esta colección. Por citar solo algunos: en el reciente Los superhéroes y el derecho, Ignacio Fernández, desde la excusa que supone hablar del superhéroe, del

\footnotetext{
${ }^{2}$ La mayor parte de las intervenciones que se realizaron en estas XXII Jornadas se encuentran recogidas en el Anuario de Filosofia del Derecho correspondiente al año 2010, tomo XXVI. En concreto, para la intervención de Mario Ruiz, dentro del Seminario sobre Cine y Derecho que se organizó, véase, Ruiz (2010a, 257-264).
} 
personaje de cómic, alcanza a pensar temas como el iusnaturalismo, el positivismo jurídico, la legalidad, la legitimidad, el poder coactivo del Estado, los principios del Estado de Derecho, los derechos fundamentales... En Blade Runner. El Derecho, guardián de la diferencia, Javier de Lucas nos sorprende con sus reflexiones sobre el tiempo y la identidad, además de, a partir de los personajes de los replicantes, los nexus, y de los blade runner, proporcionarnos pistas para entender mejor la realidad de la inmigración y el tratamiento jurídico-político de la misma y de las sociedades multiculturales. A su vez, en Brazil. Diciendo No. Reflexiones ético-políticas de Terry Gilliam, Andrés García Inda y María José González Ordovás parten de una anormalidad, Brazil, creada por un sujeto como Gilliam difícilmente clasificable, para ofrecernos reflexiones sobre el poder, el miedo, la mentira, la idiocia moral, el orden y la desobediencia...., que nos han de servir para conocer la realidad, también la del derecho, el Estado y el poder, desde la irrealidad de una sociedad distópica. Finalmente, un último ejemplo, dentro de los muchos posibles que nos ofrece esta colección, podría ser el comentario que en Las Horas. El tiempo de las mujeres realiza Octavio Salazar y del que podríamos destacar cómo consigue mantener en su texto la belleza y poesía de la película, sin por ello renunciar a la denuncia de la discriminación por razón de género y a la reivindicación política de que una sociedad no será democrática mientras no solucione esa revolución pendiente que tiene en razón del género ${ }^{3}$.

De esta forma, sin que creo que debamos olvidar que, en lo que nos puede interesar como juristas, es el cine el que ha de servir para facilitar una mejor comprensión de lo jurídico, la colección Cine y Derecho de Tirant lo Blanch sirve en un sentido y en otro; esto es, a unos y a otros: a juristas, a quienes invita a utilizar otras perspectivas diferentes de las habituales en el tratamiento de las cuestiones jurídicas, entendidas estas en sentido amplio (con sus vínculos con las cuestiones políticas, sociales, éticas...), y a los no juristas que quieran acercarse al fenómeno jurídico sin tener que agotarse en el salto de los muros casi infranqueables que, en ocasiones, la opacidad del derecho levanta al conocimiento por legos en la materia. A unos y a otros sirven estas publicaciones para ver, entender y, también, emocionarse con el derecho en el cine. Recurriendo a Mario Ruiz, este, analizando las relaciones entre el cine y el derecho desde el ámbito epistemológico, nos apunta tres elementos dependientes entre sí que creo que podemos encontrar en la colección y que sintetizan bastante

\footnotetext{
${ }^{3}$ Para el análisis de Blade Runner, Brazil y Las Horas, véanse, respectivamente, de Lucas (2002); García Inda y González Ordovás (2008); y Salazar (2006), todos ellos en la colección Cine y Derecho de Tirant lo Blanch, a los que hay que unir, sobre el tema de superhéroes y derecho, en la misma colección: Fernández (2018).
} 
correctamente estas cuestiones funcionales, esta aportación de la relación cine y derecho a las que nos referimos, y con los que -dice Mario Ruiz- "el derecho en el cine puede explicarse brevemente": relatos, historias que se cuentan y en las que predomina el elemento jurídico; análisis de técnicas narrativas que contienen argumentaciones jurídicas; y tratamiento de aspectos de la realidad relacionados con el derecho, bien a través de la realidad digamos real, o bien a través de la realidad "ficcionada" (Ruiz 2010a, 259-262; y 2010b, 6-11).

En cualquier caso, películas y temas han servido para ir avanzando en esta colección hasta un número que ya hemos visto es más que considerable y han servido, también, para acompañar la puesta en marcha y el desarrollo de otras iniciativas docentes o de divulgación y crítica del derecho. Es el caso, por ejemplo, de los cursos, jornadas y seminarios de cine y derecho(s) que, impulsados desde las distintas universidades o desde instituciones como los colegios profesionales, han tenido a los números de la colección como útiles referencias de trabajo, tanto para los mismos organizadores de la actividad como para los asistentes. Es decir, la importancia de la colección va más allá de suponer simplemente un conjunto de libros en los que se trabajan las conexiones cine y derecho. Yo creo que se le puede reconocer el valor de ser una especie de dinamizador exponencial preocupado porque -de alguna manera parafraseando algo que recoge Mario Ruiz- los conceptos-idea con los que solemos trabajar en clase se complementen - mejor que referirnos a ellos como que sirvan de complemento- con los conceptos-imagen que nos aporta el cine, de cara a facilitar una argumentación crítica sobre lo jurídico ${ }^{4}$.

Pero es que, además, sería conveniente no olvidar que este valor de la colección como dinamizador, y con él la importancia de los conceptos-imagen, no puede ser entendido hoy sin tener en cuenta las reflexiones del Lipovetsky y Serroy en torno a la transformación del cine en hipercine o a la imposición de la pantallocracia o a la, tal vez, exageración que nos puede llegar a parecer la afirmación de que las salas de cine se han vaciado puesto que ha sido la sociedad misma la que se ha llenado de cine (Lipovetsky y Serroy 2009). Como digo, tal vez lo anterior pueda resultar una exageración, pero lo que no parece serlo es afirmar que nuestro procesamiento del mundo (del mundo jurídico, en nuestro caso) está, en no pocas ocasiones, tamizado (correcta o incorrectamente) por la experiencia

\footnotetext{
${ }^{4}$ Cfr. Ruiz (2010b, 3-4), donde siguiendo a J. Cabrera, Mario Ruiz apunta la importancia de esos conceptos-imagen hasta convertirse en “auténticos, propios e independientes modelos de enseñanza, de forma directa y autónoma”, cuestión que presenta como principal en esa publicación.
} 
cinematográfica y esto es lo que, sin duda, hace más importante esta función de la colección y la conveniencia de complementar los conceptos-idea con los conceptos-imagen.

Otra cuestión que creo puede resultar interesante tratar es el tema del nombre de la colección, Cine y Derecho, donde entiendo que no resulta gratuito el orden de los términos. Si fuera Derecho y Cine podría parecer que querríamos dejar constancia de la importancia central del derecho y del papel del cine como instrumento auxiliar, el objeto que se pone al servicio del conocimiento del derecho. En este sentido, como recoge Benjamín Rivaya -y como él mismo dice, "los del grupo de Oviedo"-: "El jurídico es el punto de vista y el cine es el objeto: en otros términos, que aunque el cine tenga importancia para este conocimiento, lo fundamental no es este sino el Derecho, la comprensión del Derecho, y por eso lo citamos en primer lugar. Es decir, tratamos de poner el cine al servicio del Derecho" (Rivaya 2010, 225). Sin embargo, y aunque revisando título por título la realidad pueda ser otra -sin que esto deba entenderse como un desvalor-, lo cierto es que la colección se decanta por nombrarse como de Cine y Derecho y, como apuntaba arriba, no creo que esto responda a una mera cuestión de marketing. Y lo mismo que del título de la colección también podríamos decir del título de este seminario, donde se anteponen Cine y Literatura a Derecho.

Formas de nombrar que tienen su sentido y significado, que ni son gratuitas ni meramente estéticas, y que podemos entender que responden al hecho -suficientemente compartido- de que el cine no es una mera representación de lo real, sino que construye activamente una representación del mundo, produce realidad con su poder performativo. Quiero decir con lo anterior que con la representación cinematográfica se excede el simple juego realidad-representación, porque, parafraseando a Edgar Morin: el film representa y al mismo tiempo significa: lo real y lo irreal, el presente y lo vivido, el recuerdo y el sueño se elevan en el cine al mismo nivel mental común (Morin 1975, 234). O recurriendo a Zizek -y como plantea al inicio del documental Manual de cine para pervertidos-: con el cine - que no deja de decirnos cosas acerca de nosotros mismos- interacciona el espectador y, de alguna manera, este se acaba integrando en el desarrollo mismo de la película, lo que convierte al cine en la más pervertida de las artes que te dice "cómo desear" 5 .

${ }^{5}$ Manual de cine para pervertidos (Sophie Fiennes, 2006), que cuenta con guion y voz de Slavoj Zizek. 
Y enlazando con todo esto, pero dejando de lado esas claves psicoanalíticas que acabamos de apuntar, y volviendo a la realidad irreal del cine, como Mario Ruiz en sus trabajos afirma reivindicando la importancia de los elementos técnicos: "Hay que insistir en que el cine no solo cuenta historias sino que las recrea a través de todo un universo de elementos que dotan de sentido a una presunta realidad. Por ello, el detalle más ínfimo como puede ser un encuadre, un movimiento de cámara o un simple plano, puede esconder todo un cúmulo de ideas o mundos por descubrir" (Ruiz 2010b, 14).

Así, se trataría no solo de atender a los aspectos narrativos o, por lo menos, convendría superar una visión unidimensional del concepto de narración que la identifica con la producción literaria o histórica y, desde allí, admitir otras concepciones del discurso narrativo entre las que estaría el lenguaje cinematográfico (Ruiz 2014a, 6-9). Por eso, también se trata de atender a las cuestiones técnicas, especialmente a las imágenes, encuadres, primeros planos, tipos de montaje, movimientos de cámara, iluminación....; y a esos silencios imposibles, manifestación de la fuerza de la imagen frente a la palabra, con los que Mario Ruiz -aunque no deja de lado la conveniencia de mantener una relación equilibrada cine-derecho- parece que acaba por decantarse hacia el reconocimiento de que en la relación cine y derecho el primero cobra cierta autonomía que exige "educar ‘en’ cine” y que obliga al docente a educarse 'en' cine para comprender todos los matices y valores que la película puede ofrecer. Esto es, parece decantarse por trascender la idea de que el cine tiene un valor más que instrumental en la educación, "no es solo una herramienta; no es algo parecido a un martillo o una llave inglesa. (...), es en gran medida un arte constructivo que no se puede devaluar a la condición de mero utensilio de apoyo a las explicaciones teóricas o prácticas del profesor”; y siguiendo a Barthes y Costa concluye: "El cine, además de contener un lenguaje propio con sus reglas y convenciones establecidas, es un 'festival de emociones', y como tal, no puede ser devaluado o reducido en su complejidad, lo que permite al espectador disponer de capacidad para discernir, distinguir, opinar, elegir, interactuar" (Ruiz 2010b, 4-6).

Por eso, tanto en algunos de los trabajos de la colección Cine y Derecho -y quizás no habría que ignorar aquí la responsabilidad en la dirección de facto de la colección que tuvo Mario- como en los mismos escritos de Mario Ruiz, se nos presenta la necesidad de tener en cuenta que en la dicotomía que Benjamín Rivaya ha dado en llamar la tesis del comentario jurídico frente a la tesis de la disculpa, 
los juristas, especialmente, tendríamos que estar abiertos a educar nuestra mirada de tal forma que no solo veamos al cine -en la relación cine y derecho- como un elemento auxiliar para explicar, transmitir y entender cuestiones teóricas y realidades jurídicas. Así, al hablar de las posibilidades del cine en la didáctica jurídica, Benjamín Rivaya expone que en "la docencia de Derecho y Cine" y, más en concreto, en lo referido a la relación del discurso cinematográfico con el discurso jurídico, caben dos tesis "extremas" que, a su vez, admiten tonos más intermedios: la tesis de la disculpa y la del comentario jurídico del texto fílmico. De acuerdo a la primera, "la proyección de una película adecuada es una buena excusa (o una buena introducción) para exponer acto seguido una doctrina o una concreta institución"; mientras que la segunda, "parece otorgar más importancia al dato cinematográfico, que de mera excusa pasa a convertirse en objeto de estudio e interpretación" (Rivaya 2006, 25-26). Y si bien Rivaya ya hemos visto que propone hablar de derecho y cine, con lo que ello significa en cuanto a quién debe estar al servicio de quién, en el caso de Mario Ruiz parece apostar por -desde el equilibriono olvidar reivindicar el peso que se le ha de atribuir al dato fílmico. Otra cosa, lógicamente, serán ya la conveniencia y la oportunidad marcadas por la actividad desarrollada o por la asignatura de la que se trate; y, sobre todo, otra cosa serán no solo la conveniencia y la oportunidad, sino las posibilidades y conocimientos de que dispongamos en cada momento.

En todo caso, y en lo que se refiere a la colección, en la diversidad de trabajos que la componen podemos encontrar ambas perspectivas; y también creo que es cierto que ambas comparten el reconocimiento del potencial del cine en el sentido ya apuntado: emocionar, conmocionar al espectador e, igualmente, provocar la discusión y quién sabe si alentar cambios sociales o crear un clima favorable a la aceptación de los mismos. Si bien, y de todas formas, tampoco creo que sea conveniente olvidarnos de que como está escrito en diversos trabajos de la colección de una manera o de otra, y como bien -y pragmáticamente- sintetiza $\mathrm{M}^{\mathrm{a}}$. José Bernuz comentando La herencia del viento de Stanley Kramer, y con ella el "cine de juicios y (los) juicios de cine": "Los juicios de cine, cine son. Y no son realidad, aunque lo parezcan" (Bernuz 2013, 66).

Para ir acabando, y pensando en el futuro de ese proceso de educar la mirada que asume la colección, creo que también puede resultar de interés que esta tenga presente, de alguna manera, el decálogo metodológico que Mario Ruiz ha dejado escrito en varias de sus publicaciones a las que ya nos hemos referido (Ruiz 2010a, 262-264; y 2010b, 11-14). No se trata de respetar fielmente todos los 
puntos del decálogo; pero sí de recoger de entre ellos aquellos que entendamos que nos resultan de utilidad para desarrollar la serie Cine y Derecho de Tirant. Por ejemplo, en estas propuestas metodológicas encontramos algunas cuestiones que podrían adaptarse a la colección. Así, en el decálogo se trata sobre la estructura que conviene a una actividad de este tipo (presentación-exposición de la película y del tema, proyección, debate); sobre la necesidad de contar con un cronograma orientativo de las sesiones, con una ficha técnica de cada película y con material complementario recomendado, incluyendo la posibilidad de que se recurra a enlaces y recursos telemáticos; sobre los beneficios de cuidar el entorno físico de la proyección y, si es posible, realizar esta íntegra o, cuando menos, respetando la continuidad narrativa, teniendo como unidad mínima a la secuencia, y siempre sin interrupciones, así como en su versión original; o, entre otras cosas, sobre la conveniencia de incluir alguna película muda o no sonora, y lo mismo alguna de lo que se considera "cine periférico", "ni europeo, ni norteamericano; o al menos que no sea del llamado 'circuito comercial' o de consumo".

Algunas de estas cuestiones -que el mismo Mario Ruiz se adelanta a decir que son más bien "recomendaciones o sugerencias que no pretenden convertirse en dogmas infalibles o indiscutibles"pueden ser adaptadas a las reglas de funcionamiento de la colección. Por ejemplo, se me ocurre la idea de la estructura en tres partes, el "cuidado del entorno físico"-que ya se hace con buenas ediciones-, las referencias a recursos telemáticos...; pero, especialmente, parece que se puede atender a la cuestión de incorporar películas tanto de cine mudo o no sonoro como de ese "cine periférico" y, entre ellas, una a la que el propio Mario se refiere expresamente y que no ha tenido todavía un título en la colección: Rashomon (Akira Kurosawa, 1950). Recomendación esta última, la de "programar una buena película japonesa", que en la versión del decálogo que se recoge en su artículo del Anuario de 2010 se reconoce, incluso, como algo personal y por eso mismo hoy tiene más sentido que sea recogida: "Me permito hacer una recomendación personalísima, casi maniática: programar una buena película japonesa siempre es un acierto". Y por poner un ejemplo - no muy complicado- de estreno cercano a la fecha en que esto se escribe y con el que cumplir con la recomendación: Un asunto de familia (Hirokazu Koreeda, 2018) ${ }^{6}$.

\footnotetext{
${ }^{6}$ A partir de esta película, entre otras cosas, podemos pensar sobre cuestiones puntuales: como la delincuencia juvenil o la protección de la infancia y los servicios sociales; y, de forma más general, sobre los efectos de la intervención jurídica en instituciones sociales como la familia, sobre la anomia o sobre el significado de lo normal.
} 
Continuando con esta última recomendación de cine no comercial, a Mario Ruiz también le interesaba el cine documental y esto, de alguna manera, se podría tener presente como una línea de trabajo en la colección, si bien hay que admitir que esta -la colección, y de forma más amplia la misma editorial Tirant lo Blanch- no es ajena a este tipo de cine y a sus posibilidades en la relación cine y derecho $^{7}$. Centrándome en Mario Ruiz y el cine documental, creo que puede ser interesante destacar una de sus publicaciones que se presenta con un curioso título: "Cine documental y derechos humanos: de esquimales a militares", trabajo que concluye con un no menos curioso recuerdo, homenaje -un “deseo" dice Mario Ruiz- a García Berlanga a quien, digamos, propone que "si levantara la cabeza" se pusiera con el rodaje de una película a la que Mario ya le aporta el título: Los desahucios. Esta propuesta de película se expone como una especie de falso documental en el que García Berlanga debería recuperar la complicidad del guionista Azcona para revisitar las tramas, personajes y denuncias que se encuentran en Plácido, Bienvenido míster Marshall y El verdugo que, además, ya sabemos que es este último el título con el que Mario Ruiz inicia la colección “Cine y Derecho” en los primeros años del XXI. Un "sueño", tal vez, pero remasterizado o trabajado en edición y montaje igual no es tan imposible acercarnos a él, pues como adelanta Mario Ruiz, "en el cine no hay límites, sino imaginación y ensueño" (Ruiz 2014b, 218-240).

Más allá de imposibles, en todo caso, lo que sí que conviene compartir es que en el cine documental podemos encontrar mucho de la provocación develadora y crítica en la que Mario Ruiz -y su "frivolidad táctica" o "estratégica", pero cargada, por ello mismo, de sentido y profundidadencontraba un hábitat acogedor donde dar la vuelta a la realidad, tal y como ya nos recordaba Javier de Lucas en el afectuoso -y necesario- obituario que escribió en el número del Anuario correspondiente a 2018. Así, en el cine documental hay mucho de esa "frivolidad táctica" o "estratégica" que caracterizaba a Mario; hay mucho de esa capacidad que dice Mario tiene el cine documental de ser "un mecanismo informativo y didáctico" que refleja y expresa "la realidad con el mayor margen posible de objetividad"; pero que, y quizás no exento de una cierta paradoja, por ello mismo "contribuye a desarrollar la imaginación, la sensibilidad y las emociones" (Ruiz 2014b, 219).

\footnotetext{
${ }^{7}$ Además de títulos dentro de la colección donde se recogen referencias a películas documentales, también tenemos fuera de la misma, pero en Tirant, el trabajo centrado en los documentales y los derechos humanos que lleva por título Educar la mirada (2015), coordinado por José Antonio García Sáez y Raquel Vañó Vicedo, donde, por cierto, también encontramos una aportación de Mario Ruiz para “ver, oír, pensar los derechos humanos a través de los documentales".
} 
Finalmente, creo que también buena parte de estas sugerencias que conforman el decálogo nos remiten a lo que Mario Ruiz pensaba sobre cómo debía de ser la relación cine y derecho. En este sentido, del conjunto del decálogo extraemos una última recomendación que podría acompañar a las futuras propuestas de publicación en la colección y que Mario Ruiz, además, presenta como "una breve reflexión que sirva tanto para la docencia como a la investigación" sobre cine y derecho. Se refiere a la reivindicación de los elementos técnico-cinematográficos a la que ya hemos aludido más arriba: al valor de los primeros planos, los encuadres, los movimientos de cámara, los silencios ....; a que el cine no solo cuenta historias, sino que también las recrea "a través de todo un universo de elementos que dotan de sentido a una presunta realidad". Así, se nos advierte de que "debería evitarse la tentación de inclinar la balanza entre el componente jurídico y el cinematográfico hacia la presencia de referentes y comentarios jurídicos minimizando la presencia de los detalles cinematográficos”; y es que, como concluye Mario Ruiz: "Quizás debamos hacer un esfuerzo por superar la mera estructuración argumental y en muchas ocasiones lineal de los guiones de las películas, para disfrutar del arte cinematográfico en toda su intensidad" (Ruiz y 2010a, 264; y 2010b, 14).

En definitiva, la colección Cine y Derecho de Tirant lo Blanch, la principal y la temática, guarda una estrecha relación con una de las líneas de trabajo de Mario -en realidad con algo más que una línea de trabajo-: con aquella que reivindica el cine y sus posibilidades (silencios y fundidos en negro incluidos) más allá de lo que nos pueden aportar la palabra, los aspectos narrativos y la literatura. Resumiendo, como afirma Zizek: "Para entender el mundo actual necesitamos del cine, literalmente. Solo en el cine encontramos la dimensión crucial que no estamos listos para confrontar en nuestra realidad. Si buscas aquello que en la realidad es más real que la misma realidad, busca en la ficción cinematográfica"8.

\footnotetext{
${ }^{8}$ Recogido de la parte final del documental Manual de cine para pervertidos (Sophie Fiennes, 2006).
} 


\section{Bibliografía}

BERNUZ, Ma $\mathrm{M}^{\mathrm{a}}$ J.; "Cines de juicios y juicios de cine”, en GARCÍA INDA, A. y BERNUZ BENEITEZ, Ma . J. (coords.), Herencia del viento. La lucha de los derechos, Valencia, Tirant lo Blanch, 2013, pp. 49-68.

FERNÁNDEZ SARASOLA, I.; Los superhéroes y el derecho, Valencia, Tirant lo Blanch, 2018.

GARCÍA INDA, A. y GONZÁLEZ ORDOVÁS, Ma . J.; Brazil. Diciendo No. Reflexiones ético-politicas de Terry Gilliam, Valencia, Tirant lo Blanch, 2008.

GARCÍA SÁEZ, J. A. y VAÑÓ VICEDO, R. (eds.); Educar la mirada. Documentales para una enseñanza crítica de los derechos humanos, Valencia, Tirant lo Blanch, 2015.

LIPOVETSKY, G. y SERROY, J.; La pantalla global. Cultura mediática y cine en la era hipermoderna, trad. A. Prometeo Moya, Barcelona, Anagrama, 2009.

LUCAS, J. de; Blade Runner. El Derecho, guardián de la diferencia, Valencia, Tirant lo Blanch, 2002.

MORIN, E.; El cine o el hombre imaginario, trad. R. Gil Novales, Barcelona, Seix Barral, 1975.

RIVAYA, B.; "Derecho y Cine. Sobre las posibilidades del cine como instrumento para la didáctica jurídica”, en PRESNO LINERA, M. A. y RIVAYA, B. (coords.), Una introducción cinematográfica al Derecho, Tirant lo Blanch, 2006, pp. 1228.

RIVAYA, B.; “Algunas preguntas sobre Derecho y Cine”, Anuario de Filosofia del Derecho, 26, 2010, pp. 219-230.

RUIZ SANZ, M.; “Es conveniente enseñar derecho a través del cine?”, Anuario de Filosofía del Derecho, 26, 2010a, pp. 257-264.

RUIZ SANZ, M.; “La enseñanza del Derecho a través del cine: implicaciones epistemológicas y metodológicas”, Revista de Educación y Derecho, 2, 2010b, pp. 1-16.

RUIZ SANZ, M.; "Instruir en Derecho y Cine: una apuesta entre elecciones y pasiones", Revista de Educación y Derecho, 9, 2014a, pp. 1-22.

RUIZ SANZ, M.; "Cine documental y derechos humanos: de esquimales a militares", Teoría y derecho. Revista de pensamiento jurídico, $15,2014 \mathrm{~b}$, pp. 218-242

SALAZAR BENÍTEZ, O.; Las Horas. El tiempo de las mujeres, Valencia, Tirant lo Blanch, 2006.

SAN MARTÍN, D. y SUSÍN, R.; "Introducción: el riesgo a escena”, en SAN MARTÍN SEGURA, D. y SUSÍN BETRÁN, R. (coords.), Derecho y política en la sociedad del riesgo. 8 propuestas de cine, Servicio de publicaciones de la Universidad de La Rioja, 2009, pp. 15-32. 